\title{
Scanning electron microscopic observations on the head morphology of seven different leptocephali belonging to six eel families (Anguilliformes)
}

\author{
S. Appelbaum ${ }^{1,2} \&$ R. Riehl ${ }^{3}$ \\ ${ }^{1}$ Jacob Blaustein Institute for Desert Research, Ben-Gurion University of the Negev; \\ Sede Boker - 84993, Israel \\ ${ }^{2}$ University of British Columbia, Department of Animal Sciences, Faculty of Agricultural \\ Sciences; Vancouver, B. C., V6T 2A2, Canada * \\ ${ }^{3}$ Institut für Zoologie (Morphologie \& Zellbiologie) der Universität Düsseldorf; D-W-4000 \\ Düsseldorf, Federal Republic of Germany
}

\begin{abstract}
Scanning electron microscopy observation was carried out on head morphology, number and construction of teeth, nostril position and the presence of neuromasts of seven species of leptocephali from six families of the Anguilliformes. The number and form of the teeth vary within the different families, from 76 teeth in Gnathophis sp. (Congridae) to 32 teeth in Anarchias yoshiae (Muraenidae). In most of the genera the number of teeth on upper and lower jaws is almost equal, except in Gnathophis sp., Anguilla anguilla and Kaupichthys hyoproroides. The unusual size and form of the leptocephali's teeth led us to speculate on the feeding behaviour of these larvae. Tentatively we suggest that the tooth formation of the leptocephali may act as a filtering system, rather than as a predatory apparatus, as its vicious appearance might suggest. Given the largely passive nature of a filtering system, the larvae would be able to concentrate on their migration. Of all the investigated leptocephali, only Nemichthys scolopaceus shows one olfactory opening on each side of the head, whilst all the other species show two openings. The data obtained from these investigations suggest that teeth form as well as form and position of the nostrils are characteristics of the genera, and possibly also of the species.
\end{abstract}

\section{INTRODUCTION}

The life-cycle mystery of anguilliform fish has aroused interest among investigators world-wide for many years. However, still not much is known on the taxonomy and the biology of anguilliform leptocephali; some knowledge on the taxonomy is, for example, presented by Smith (1979). In our paper, some more details of the morphology of the head, especially of the dentition, are provided, and the particularities of the jaws throw some more light on the possible feeding behaviour of the leptocephali. The food and feeding of the larval stage, the leptocephalus, still remain puzzling.

Whilst the feeding of glass eels of Anguilla spp. has become routine, no report exists of any success in feeding younger marine stages. Moreover, of the many larval specimen

- Present address for all correspondence 
caught in the ocean during years of investigation, none have shown signs of food items in the digestive tract of leptocephali (Kracht \& Tesch, 1981; Kracht, 1982; Pfeiler, 1986; Bruslé, 1989). Suggestions have been made on the food and feeding habits of leptocephali. Hulet (1978), Pfeiler (1986) and, more recently, Mochioka \& Iwamizu (Paper presented at "Eifac/FAO Working Party on Eels", in Porto, 1989) and Westerberg (1990); the latter hypothesized that discharged appendicularia houses are the main food of leptocephali. However, this question still remains unanswered. Our presentation is an additional step towards solving the mystery of leptocephali food and feeding.

\section{MATERIAL AND METHODS}

Most of the leptocephali examined were collected during the 1979 Eel Expedition by the German research vessel "Anton Dohrn" (cf. Tesch, 1982). Only the leptocephali of Anguilla anguilla were caught during a 1991 cruise of the German research vessel "Meteor".

Examination of specimens caught in the Sargasso Sea either by MOCNESS or IKMT included four Anarchias yoshiae (Stat. 5526, 5615, 5695, 5813), two Serrivomer beani (5666, 5689), five Nemichthys scolopaceus $(5688,5689)$, one Ariosoma balearicum (5698), one Kaupichthys hyoproroides (5717) and one Gnathophis sp. (5781). Details on the position of the stations, gear, date and time are provided by the cruise report (Tesch, 1982).

The fish collected were identified on board shortly after the hauls, using the identification key of Smith (1979), and then preserved in formaldehyde (4\% buffered with borax) and sea water. Later, the formalin was removed and replaced by $70 \%$ isopropanol, in which the material was kept for investigation. Length measurements were standard length from the tip of the snout to the end of the hypural. Head length was measured to the base of the pectoral fin. The ratio of eye diameter to the head length was determined as eye index. The leptocephali were collected, using both a modification of the Isaacs Kidd Midwater Trawl (IKMT) (opening $6.2 \mathrm{~m}$ ), length $9.0 \mathrm{~m}$, and mesh-size of $500 \mu \mathrm{m}$, including time-depth recorder) and a multiple Opening and Closing Net and Environmental Factor Sensing System (MOCNESS) (opening $1.0 \mathrm{~m}$ and mesh-size $350 \mu \mathrm{m})$.

For scanning electron microscopy the heads of the leptocephali were dehydrated in a graded acetone series, then dried in a Balzers critical point dryer, mounted on brass supports with hot glue and coated with a $25 \mathrm{~nm}$ thick layer of gold in an Emscope SC 500 sputter coater. Examinations were carried out with a Leitz AMR 1000 scanning electron microscope.

\section{RESULTS}

\section{Anguilla anguilla (Linnaeus, 1758) - Anguillidae}

Two leptocephali of $A$. anguilla, measuring $65 \mathrm{~mm}$ and $73 \mathrm{~mm}$ total length, were examined. They were caught on 25 October 1991, using IKMT, in the Bay of Biscay and off the Iberian continental shelf, at a depth of $1500-2000 \mathrm{~m}$. The head was short and very stocky showing large eyes with a diameter of $1.1 \mathrm{~mm}$ (Fig. 1). The eye index was 2.8. In 

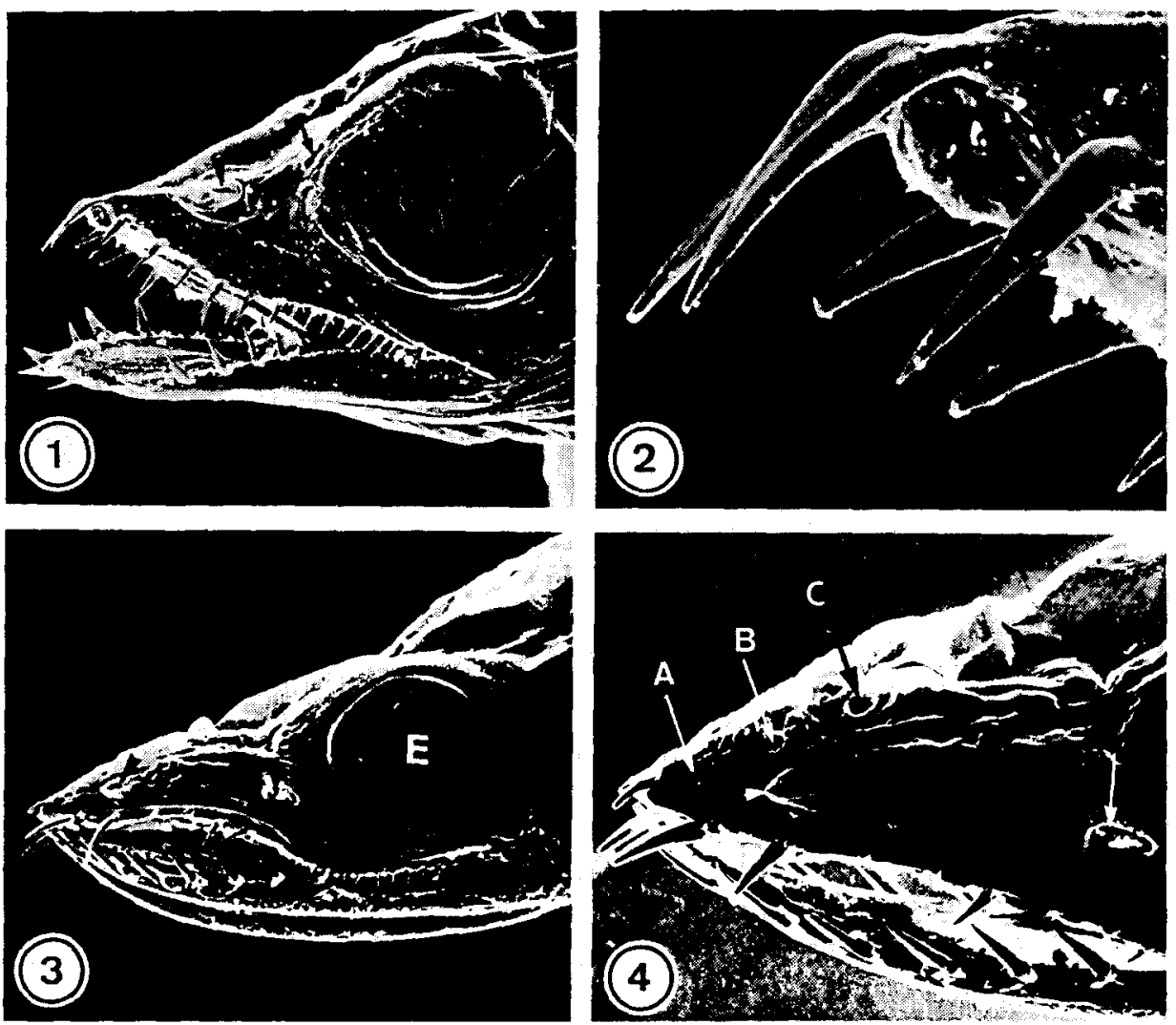

Figs 1-2. Anguilla anguilla (Anguillidae). 1: Head with nostrils. Note the front pair of teeth in the upper jaw (25:1). 2: Higher magnification of the round teeth of the upper jaw (95:1)

Figs 3-4. Kaupichthys hyoproroides (Xenocongridae). 3: Head with ingestion and egestion openings extremely far apart (23:1). 4: Front part of the head with round teeth (55:1)

A-C: neuromasts; $\mathrm{E}=$ eye; arrowhead $=$ ingestion opening; arrow = egestion opening

the first leptocephalus, a total of fifty-six teeth were counted, 32 teeth on the upper jaw and 24 on the lower jaw; in the second leptocephalus fifty teeth, 30 in the upper and 20 in the lower jaw. Most of the front teeth were prominent, especially the front pair of the upper jaw which are clearly enlarged and form pincers. In $A$. anguilla all teeth are round in cross section (Fig. 2). Two nostrils occur on each side of the head. The ingestion opening is situated in the middle of the snout, whereas the egestion opening almost touches the frontal margin of the eye (Fig. 1). The ingestion opening shows a velum. Some neuromasts are spread over the head.

\section{Kaupichthys hyoproroides Strömman, 1896 - Xenocongridae}

A $K$. hyoproroides leptocephalus measuring $51 \mathrm{~mm}$ in total length was studied. The head was conical and elongated, exhibiting round, large eyes with a diameter of $0.78 \mathrm{~mm}$ 
(Fig. 3). The eye index was 4.1. The mouth of $K$. hyoproroides had an unusual shape; while at the posterior part the jaws could approach each other; at the more anterior part they remained apart. In the anterior part of both jaws the triangular teeth, some of which were interlocking, protruded (Fig. 3). In the posterior part of the mouth, only the upper jaw was provided with numerous small, cylindro-conical teeth (Figs 3,4 ). In total, sixtytwo teeth were counted, but only 16 occurred in the lower jaw, all the other teeth were in the upper jaw. Each side of the head exhibited two nostrils which were situated close to the jaw edge, directly above the lips of the upper jaw (Fig. 4). The ingestion and egestion openings were positioned extremely far from each other. The anterior opening was located almost on the tip of the snout, showing a skinfold, whereas the egestion opening was found in front of the eye. Three pairs of neuromasts were found, lined up one after the other. The first was situated between the tip of the snout and the ingestion opening, the second directly above, and the third, obliquely behind this opening (Fig. 4).

\section{Anarchias yoshiae Kanazawa, 1952 - Muraenidae}

Four $A$. yoshiae leptocephali, measuring $39,40,40$ and $45 \mathrm{~mm}$, were examined. The heads of these species were stocky and short with large eyes $0.63 \mathrm{~mm}$ in diameter (Fig. 5). The eye index was 3.9. All four specimens had thirty-two teeth, 16 each in the upper and lower jaws. Most of the teeth were very prominent. The front pair of teeth of each jaw projected nearly horizontally (Figs 5,6 ). In A. yoshiae, all teeth were cylindro-conical (Fig. 6). Two nostrils were present on each side of the head. The ingestion and egestion openings were approximately of the same size, but the ingestion opening had a skinfold. The nostrils were wider apart. The ingestion opening lay in the middle of the snout, whereas the egestion opening was located diagonally opposite the eye (Fig. 6). Three pairs of neuromasts were found: the first was situated in front of the ingestion opening, the second directly above it, and the third directly anterior to the front margin of the eye.

\section{Nemichthys scolopaceus Richardson, 1848 - Nemichthyidae}

Five leptocephali of $N$. scolopaceus measuring 22, 25,37, 40 and $55 \mathrm{~mm}$ were examined. The contour of the head was concave anterior to the eye, and the snout was sharp and elongated (Fig. 7). The large eyes were round, having a diameter of $0.6 \mathrm{~mm}$. In this species, the eye index was 3.8. Thirty-eight teeth in total were found, 20 in the upper jaw and 18 in the lower jaw. The front teeth were long, sharp and interlocking, showing a triangular shape (Fig. 8). Two pairs of the front teeth of each jaw projected in a nearly horizontal plane (Figs 7,8 ). The teeth towards the back of the jaws were significantly shorter and round. In N. scolopaceus, each side of the head bore only a single nostril! The nostrils were prominent (Fig. 7). They were situated directly in front of the eyes where the head showed a concave dorsal profile. No neuromasts were found.

\section{Ariosoma balearicum (De la Roche, 1809) - Congridae}

Of $A$. balearicum, we investigated a single specimen, measuring $75 \mathrm{~mm}$ in total length. The head was small, short and elongated with large round eyes of $0.55 \mathrm{~mm}$ 

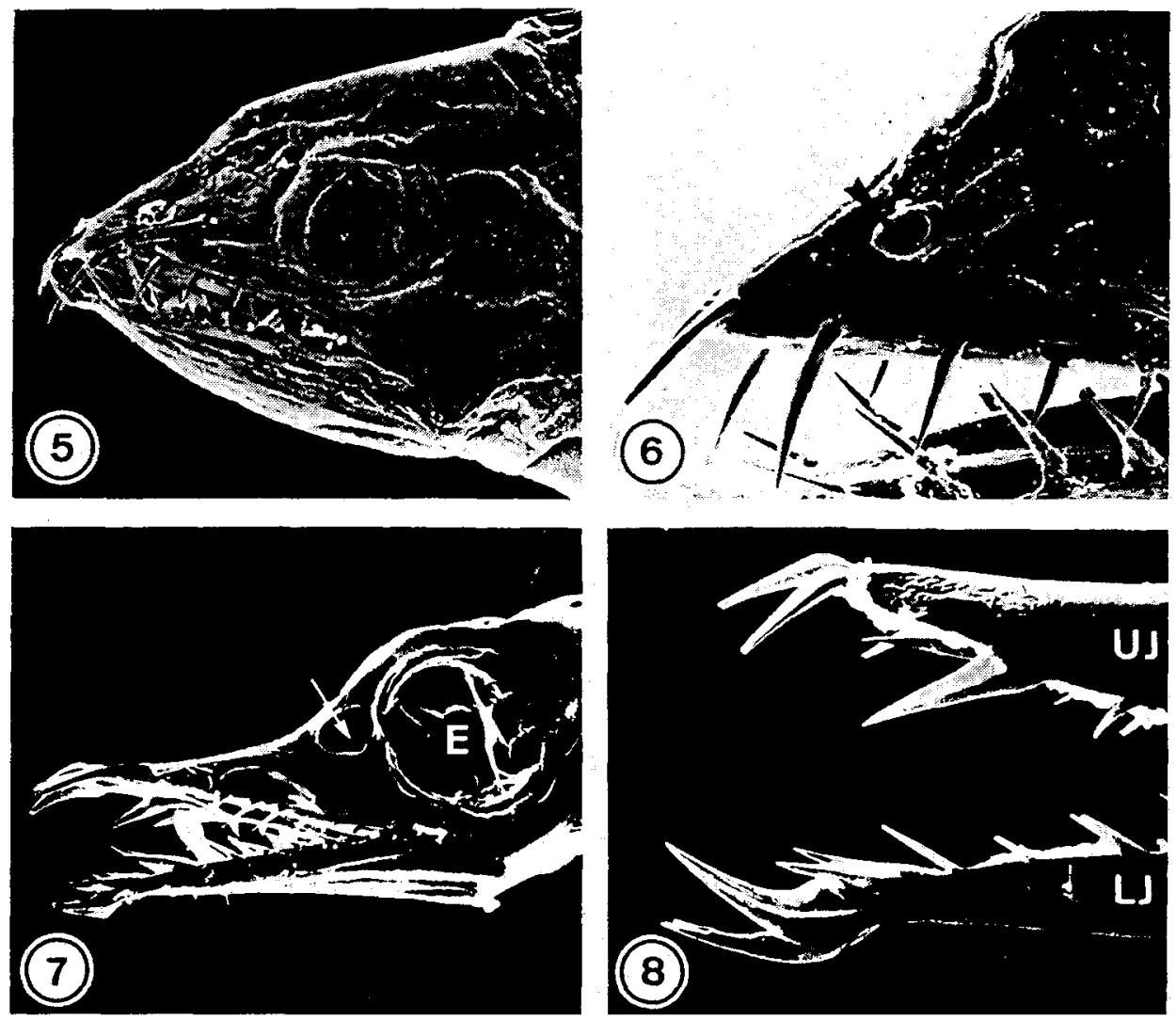

Figs 5-6. Anarchias yoshiae (Muraenidae), 5: View of the head. The shrinkage is caused by fixation and long storage in ethanol $(30: 1)$. 6: Higher magnification of the round teeth $(65: 1)$

Figs 7-8. Nemichthys scolopaceus (Nemichthyidae). 7: Head with only a single nostril (white arrow; 30:1). 8: Upper jaw (UL) and lower jaw (LJ) with the front, triangular teeth (85:1)

$\mathrm{E}=$ eye $_{i}$ arrowhead $=$ ingestion opening; arrow $=$ egestion opening

diameter. The eye index was 3.4. The snout was prominent (Fig. 9). We counted a total of fifty teeth, 26 located in the upper jaw and 24 in the lower jaw. The teeth were prominent and the front pair of each jaw projected in a nearly horizontal plane (Fig. 10). All teeth were blade shaped, and triangular in cross section (Fig. 10). On each side of the head, there were two nostrils. The ingestion opening was smaller than the egestion opening (Fig. 10). Both nostrils were located a short distance from the eyes and lay close together. We found no neuromasts on the head, but we detected an unknown organ lying between the nasal ingestion openings (cf. Fig. 11). After a close-up investigation, we consider that this organ may act as a shelter for neuromasts (Fig. 12). 

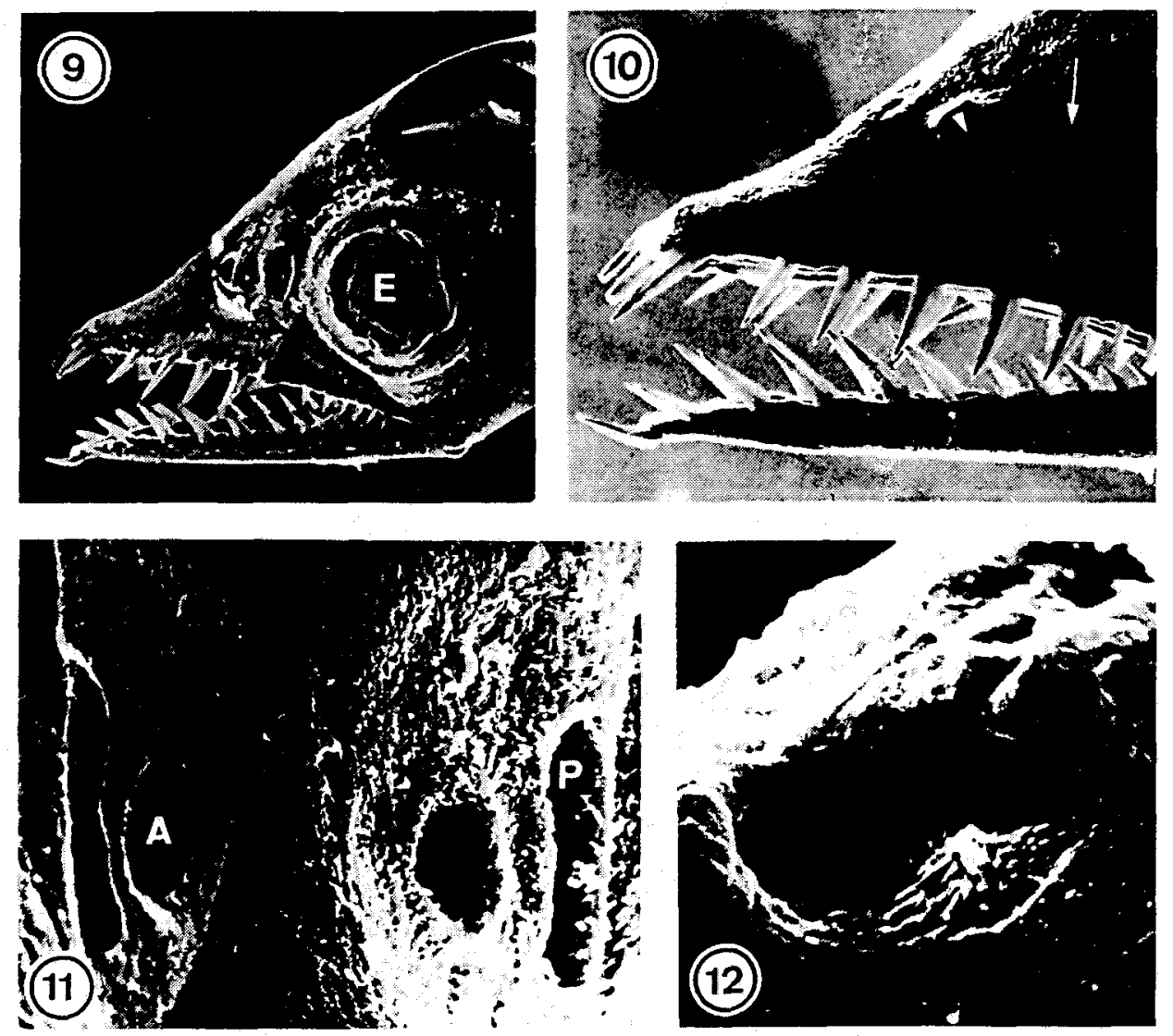

Figs 9-12. Ariosoma balearicum (Congridae). 9: Head (33:1), 10: Triangular teeth and the nostrils (52:1). 11: Front view with a hitherto unknown organ (arrow; 140:1). 12: Side view of the unknown organ, perhaps a hidden neuromast (arrowhead)

$A$, and arrowhead = ingestion opening; $E=$ eye; $P$, and arrow = egestion opening

\section{Gnathophis sp. - Congridae}

A single leptocephalus of Gnathophis, measuring $75 \mathrm{~mm}$ in total length, was investigated. The head was short, conical and stocky, with small, slightly oval eyes with a diameter of $1.0 \mathrm{~mm}$ (Fig. 13). In this species the eye index was 6.1. Seventy-six teeth in total were found: 44 were situated in the upper jaw and 32 in the lower jaw. The teeth were less prominent than those of Ariosoma balearicum, but the front pair of the upper jaw also projected in a nearly horizontal plane. All teeth were triangular (Fig. 14). The front teeth were evidently larger than those towards the back of the jaw. Two nostrils were located on each side of the head. The ingestion and egestion openings were oval and nearly the same size as each other (Fig. 14). Both nostrils were situated in front of the eyes, but were at a further distance from the eyes than those of $A$. balearicum. The 
ingestion opening was in the middle of the snout. The ingestion and egestion openings were widely separated. Neuromasts were not found.

\section{Serrivomer beani Gill \& Ryder, 1883 - Serrivomeridae}

Two leptocephali of $S$. beani measuring 40 and $51 \mathrm{~mm}$ in total length, were investigated. The head was elongated with a sharp snout (Fig. 15). In the 40-mm specimen the head showed anterior to the eye a concave dorsal profile. The eyes were small and round, with a diameter of $0.82 \mathrm{~mm}$. The eye index was 5.5 . The mouth was large with a groove indicating a predator. A total of forty-six teeth were counted; 24 were situated in the upper jaw and 22 in the lower jaw. The teeth were prominent, extremely pointed, triangular, and interlocking (Figs 16, 17). As in many other leptocephali, the teeth inclined forward (Fig. 15). The nasal organ was small and close to the eye. Two nostrils occurred on each side of the head. Both nostrils were situated directly in front of the eyes, whereby the egestion opening almost touched the eye (Figs 15, 17). The ingestion and egestion openings were located very close to each other. No neuromasts were found in either specimen.

All head characteristics of the examined leptocephali are summarized in Table 1.

\section{DISCUSSION}

In the present study, scanning electron microscopy observation was carried out on seven species of leptocephali from six families of anguilliform fishes. The observations concentrated on head form, number and construction of teeth, nostril position and the presence of neuromasts. The number and form of the dentition varies within the different families. The leptocephalus of Gnathophis sp. (Congridae) has more than twice the number of teeth $(\mathrm{n}=76)$ than the leptocephalus of Anarchias yoshiae (Muraenidae) has $(n=32)$. All other genera investigated show a number of teeth somewhere between these two. In most of the genera, the number of teeth in upper and lower jaws is almost equal, except in Gnathophis sp., Anguilla anguilla and Kaupichthys hyoproroides where there are more teeth in the upper jaw than in the lower. More remarkable is $K$. hyoproroides (Xenocongridae) which has 46 teeth in the upper jaw - almost three times as many as in the lower jaw - where there are only 16.

Another interesting phenomenon is the form of the teeth and their size. In two of the families, the Anguillidae and the Muraeidae, all teeth are round in cross section; in the families Xenocongridae and Nemichthyidae the front teeth are triangular and larger than those at the back which are round; and in the last two families, Congridae and Serrivomeridae, which are, within the Anguilliformes, systematically far from the other families (Nelson, 1984), all teeth are triangular, particularly in Serrivomer beani, where they appear to be extremely strong (compare Bauchot, 1959). As only a few specimen were investigated, we are not able to conclude that tooth formation might be used as a means of family identification; however, we cannot exclude such a possibility.

The very unusual formation of the leptocephali dentition prompts speculation on the feeding behaviour of these larvae. Westerberg (1990) considered that "The only way in which leptocephali teeth can be subjected to compression simultaneously in both jaws is if the mouth is opened wide and the dentition is used as a fork which is pushed up into the 

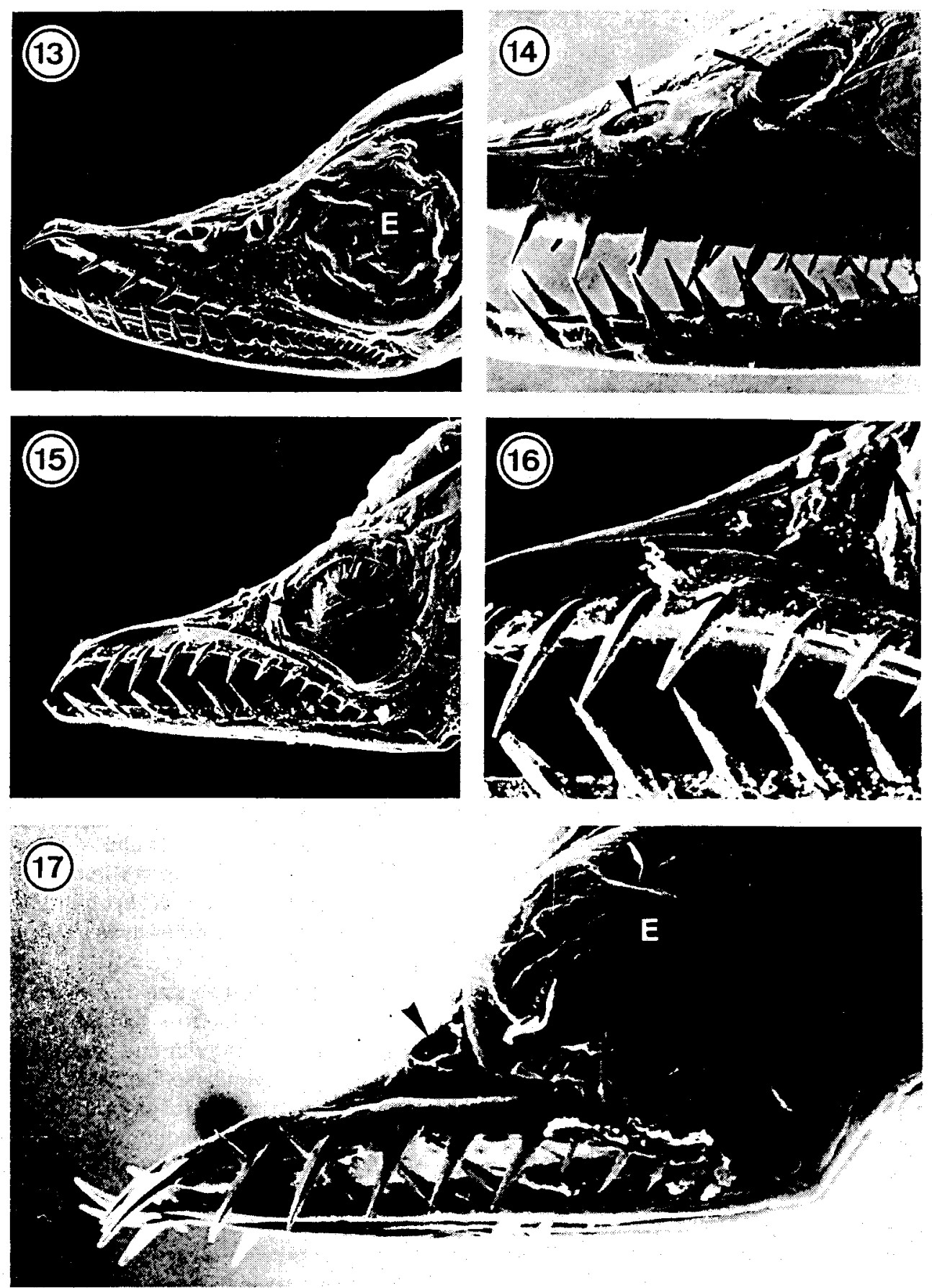
food item". He continued, "This should be a suitable way to grab and hold a soft, viscoelastic object".

Presuming that a food item is hooked by the protruding teeth raises the question of how these food items could be pushed backwards into the mouth. Moreover, since the teeth, all along the jaw, point forward, it is difficult to understand how the food items could, passively or actively, be moved backwards towards the esophagus.

Since leptocephali migrate - some species over very long distances - it is difficult to understand how these fragile larvae can afford 'valuable' time for predation, during which their predetermined migration must be completed. The only explanation is that they drift. However, this passive migration has been questioned by more recent studies (Kracht \& Tesch, 1981; Tesch et al., 1986; Bast \& Strehlow, 1990). The appearance of the very large teeth gives, naturally, the impression that the corresponding food items would be large. Thus, eel larvae would act as typical predatory animals, either lurking for appropriate prey to come, or actively searching for it. Such behaviour may strongly hinder the predetermined migration. For this reason, we speculate that the migratory eel larvae relies more on continuous feeding by filtration while simultaneously migrating.

Our tentative speculation is that the tooth formation of leptocephali acts more like a filter system, functioning in a way that allows the fish to concentrate on migration, while food items of selected size can pass through the spaces between the teeth and be ingested while the fish are swimming. Such food items would be of the magnitude of nanoplankton, including protozoa, algae, yeast cells etc.

Our hypothesis that the teeth of leptocephali act as a passive sieve apparatus for food items can be supported (1) by Schmidt (1925) who noted that the gut of protoleptocephali of Anguilla rostrata contained food consisting of minute organisms, (2) by Kubota (1961) who found minute particles, thought to be phytoplankton, in the gut of Conger myriaster, and (3) by Mochioka \& Iwamizu (1989), who concluded from their study on eight leptocephali species from five families that these larvae feed on the pellets of small planktonic crustaceans.

Hulet (1978) and Pfeiler (1986) have suggested that the teeth of leptocephali are an instrument for keeping particles out of the mouth as the fish absorb diluted organic material from the water. Our conclusions contradict this suggestion and also the suggestion that leptocephali, because of their large teeth, may capture larger prey.

According to Berndt (1938), the gut length of A. anguilla leptocephalus amounts to $63 \%$ of its body length $(75 \mathrm{~mm})$; at the glass eel stage it decreased to $38 \%$. Schoth (1982) found for leptocephali of $A$. rostrata and $A$. anguilla, a ratio of $79.65 \%$ and $79.11 \%$, respectively for intestinal length to total body length. There was also a slight decrease in the length of the intestine with increasing body length in both species. During its

Figs 13-14. Gnathophis sp. (Congridae). 13: Head with nostrils (26:1). 14: Higher magnification of the triangular teeth and the nostrils (50:1)

Figs 15-17. Serrivomer beani (Serrivomeridae). 15: Head with open mouth and nostrils (28:1). 16: All teeth are extremely triangular $(65: 1)$. 17: Head with closed mouth, the prominent teeth forming a trap (52:1)

$\mathrm{E}=$ eye; arrowhead = ingestion opening; arrow = egestion opening 


\begin{tabular}{|c|c|c|c|c|c|c|c|}
\hline 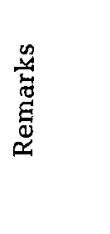 & 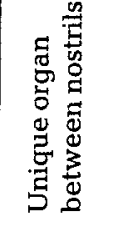 & 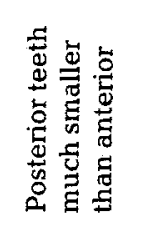 & 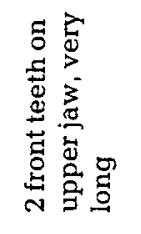 & 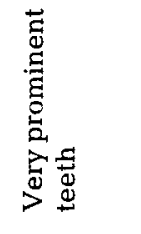 & \multicolumn{2}{|c|}{ 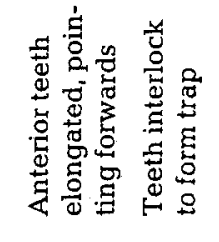 } & 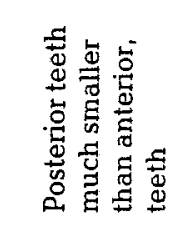 \\
\hline 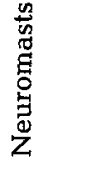 & $\begin{array}{l}\frac{0}{0} \\
\frac{0}{50} \\
0 \\
0 \\
0 \\
\frac{0}{4}\end{array}$ & $\begin{array}{l}\frac{0}{0} \\
\frac{0}{50} \\
5 \\
0 \\
0 \\
\square\end{array}$ & $\begin{array}{l}\frac{0}{0} \\
\frac{0}{0.0} \\
\frac{0}{5}\end{array}$ & $\begin{array}{l}\text { 号 } \\
\text { 吾 } \\
\text { m }\end{array}$ & 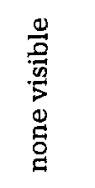 & 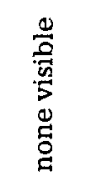 & 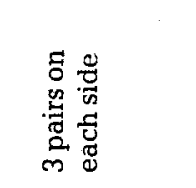 \\
\hline 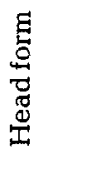 & 营 & $\begin{array}{l}\overrightarrow{\mathrm{s}} \\
\frac{5}{n}\end{array}$ & 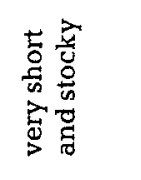 & 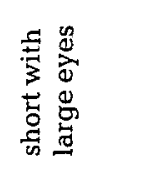 & 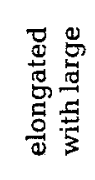 & 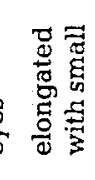 & 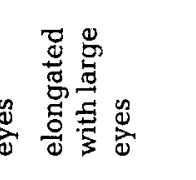 \\
\hline 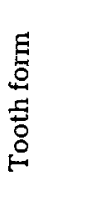 & 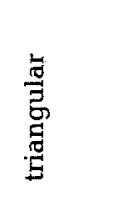 & 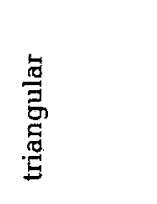 & 莺 & $\begin{array}{l}\text { : } \\
\text { 总 }\end{array}$ & 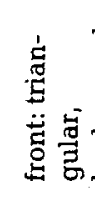 & 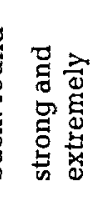 & 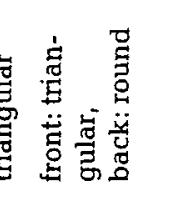 \\
\hline 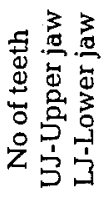 & 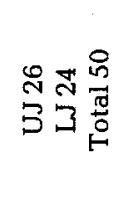 & 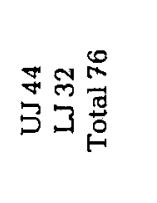 & 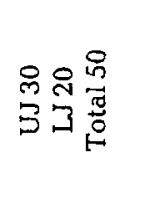 & 央电 & 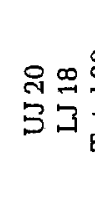 & İ & $\begin{array}{l}0.00 \\
35 \frac{0}{0} \\
5\end{array}$ \\
\hline 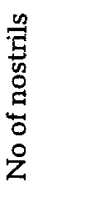 & 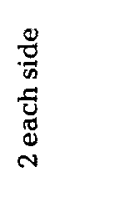 & 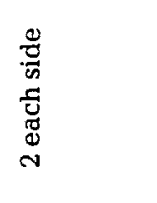 & 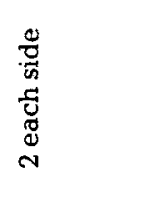 & 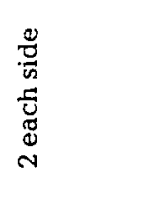 & $\begin{array}{l}\frac{0}{0} \\
\frac{5}{5} \\
5 \\
0 \\
0 \\
0 \\
-1\end{array}$ & 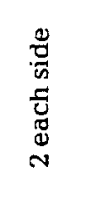 & $\begin{array}{l}\frac{0}{0} \\
\frac{0}{n} \\
\frac{\pi}{0} \\
0 \\
0 \\
\sim\end{array}$ \\
\hline 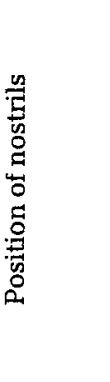 & 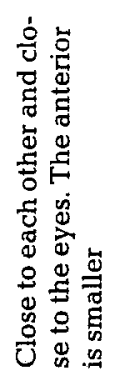 & 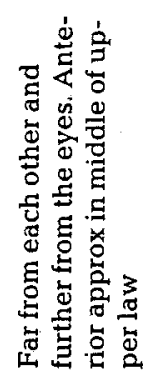 & 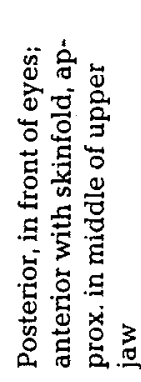 & 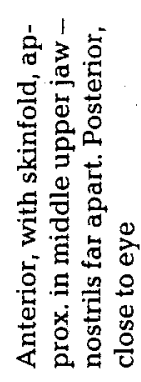 & 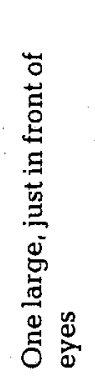 & 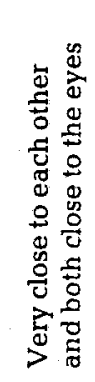 & 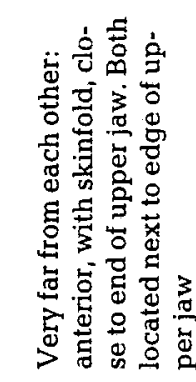 \\
\hline 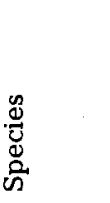 & 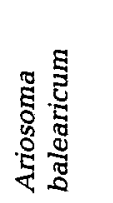 & 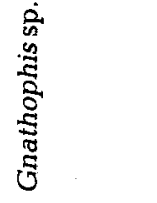 & 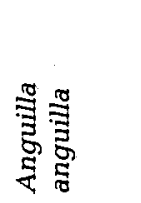 & 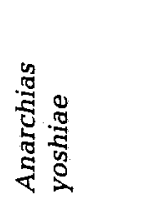 & 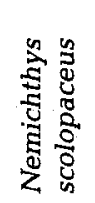 & 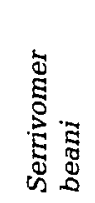 & 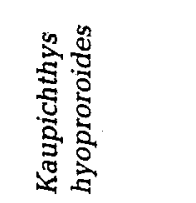 \\
\hline
\end{tabular}


leptocephalus stage, $A$. anguilla has the longest intestine in relation to body length (Tesch, 1983). A long intestine would support the assumption that leptocephali feed on minute organisms, rather than on larger prey items.

Böttger (1982) found in the 0-100 $\mathrm{m}$ layer of the northern and southern areas of the Sargasso Sea median densities of copepod nauplii of 3600 and 1100 individuals $/ \mathrm{m}^{3}$. These concentrations are similar to those reported for an area of larval fish development in the North East Pacific (Arthur, 1977). The youngest larvae of the A. anguilla and $A$. rostrata were found to occur mainly in the southern part of the Sargasso Sea (Schoth \& Tesch, 1982). Though it would seem that concentrations of planktonic organisms as high, found in the spawning area of the European and American eel, could serve as food for the leptocephali, the fact is that so far no visible food items have been found in their not yet fully developed digestive systems.

All this leads to the conclusion that leptocephali feed on smaller items such as protozoa and items below that size which are more difficult to observe and detect in the gut of a caught leptocephalus.

With regard to the olfactory organ of all the investigated leptocephali, the Nemichthys scolopaceus is an exception. It shows only one olfactory opening on each side of the head, whilst all the other species show two - those for ingestion and egestion. It is possible that $N$. scolopaceus does not need to rely on the sense of smell to search for food. Adults of $N$. scolopaceus are known to feed on larger prey, mainly shrimps, which are trapped by the numerous tiny teeth in the eel jaws (Appelbaum, 1982).

The position of the nostrils on each side of the head differs among the investigated species. While in Ariosoma balearicum they are close to each other, in Anarchias yoshiae and Kaupichthys hyoproroides they are further apart. The question remains as to whether the position of the notrils would indicate that leptocephali have a good or a bad sense of smell. Electron microscopy investigation on the olfactory epithelium could provide the answer.

The data obtained from our investigation suggest that teeth form, as well as form and position of the nostrils, are characteristics of the genera, and possible also of the species.

Acknowledgements. Dr. D. Smith of the Marine Biochemical Institute of the University of Texas, Galvestone, was instrumental in the leptocephali identification on board. We thank Dr. F. W. Tesch, Hamburg, and J. C. Antunes, Porto, for providing Anguilla anguilla specimens, and G. Reuter, Düsseldorf, for preparing the micrographs.

\section{LITERATURE CITED}

Appelbaum, S., 1982. Studies on food organisms of pelagic fishes as revealed by the 1979 North Atlantic Eel Expedition. - Helgoländer Meeresunters. 35, 357-367.

Arthur, D. K., 1977. Distribution, size and abundance of microcopepods in the California Current system and their possible influence on survival of marine teleost larvae. - Fish. Bull. U.S. 75, $601-611$.

Bast, H.-D. \& Strehlow, B., 1990. Length composition and abundance of eel larvae, Anguilla anguilla (Anguilliformes: Anguillidae), in the Iberian Basin (northeastern Atlantic) during July-September 1984. - Helgoländer Meeresunters. 44, 353-361.

Bauchot, M.-L., 1959. Etude des larves leptocéphales du groupe de Leptocephalus lanceolatus Strömman et identification à la famille des Serrivomeridae, - Dana Rep. 48, 1-148.

Berndt, O., 1938. Morphologie und Histologie des Rumpfdarmes von Anguilla fluviatilis und die Veränderungen desselben im Individualzyklus. - Zool. Jb. (Anat. Ontogenie Tiere) 64, 437-482. 
Böttger, R., 1982. Studies on the small invertebrate plankton of the Sargasso Sea. - Helgoländer Meeresunters. 35, 369-383.

Bruslé, J., 1989. Les migrations au cours du cycle biologique des anguilles: de l'aire de ponte marine à la colonisation des milieux continentaux (leptocephales, civelles, anguilles jaunes). - Oceanis $15,181-195$.

Hulet, W. H., 1978. Structure and functional development of the eel leptocephalus Ariosoma balearicum (De la Roche, 1809). - Phil. Trans. Soc. (B) 282, 107-138.

Kracht, R., 1982. On the geographic distribution and migration of I- and II-group eel larvae as studied during the 1979 Sargasso Sea Expedition. - Helgoländer Meeresunters. 35, 321-327.

Kracht, R. \& Tesch, F.-W., 1981. Progress report on the eel expedition of R. V. "Anton Dohrn" and R. V. "Friedrich Heincke" to the Sargasso Seas 1979. - Environ. Biol. Fish. 6, 371-375.

Kubota, S. S., 1961. Studies on the ecology, growth and metamorphosis in conger eel Conger myriaster (Brevoort). - J. Fac. Fish. Mie Univ. 5, 190-370.

Nelson, J., 1984. The fishes of the world. Wiley, New York, 523 pp.

Pfeiler, E., 1986. Towards an explanation of the developmental strategy in leptocephalous larvae of marine teleost fishes. - Environ. Biol. Fish. 15, 3-13.

Schmidt, J., 1925. The breeding places of the eel. - A. Rep. Smithson. Instn 1924, 279-316.

Smith, D. G., 1979. Guide to the leptocephali (Elopiformes, Anguilliformes and Notacanthiformes). NOAA Tech. Rep. NMFS Circ. 424, 1-39.

Schoth, M., 1982. Taxonomic studies on the 0-group eel larvae (Anguilla sp.) caught in the Sargasso Sea in 1979. - Helgoländer Meeresunters. 35, 279-287.

Schoth, M. \& Tesch, F.-W., 1982. Spatial distribution of 0-group eel larvae (Anguilla sp.) in the Sargasso Sea. - Helgoländer Meeresunters. 35, 309-320.

Tesch, F.-W., 1982. The Sargasso Sea Eel Expedition 1979. - Helgoländer Meeresunters. 35, 263-277.

Tesch, F.-W., 1983. Der Aal. Parey, Hamburg, 340 pp.

Tesch, F. W., Niermann, U. \& Plaga, A., 1986. Differences in developmental stage and stock density of larval Anguilla anguilla off the west coast of Europe. - Vie Milieu 36, 255-260.

Westerberg, H., 1990. A proposal regarding the source of nutrition of leptocephalus larvae. - Int. Revue ges. Hydrobiol. 75, 863-864. 